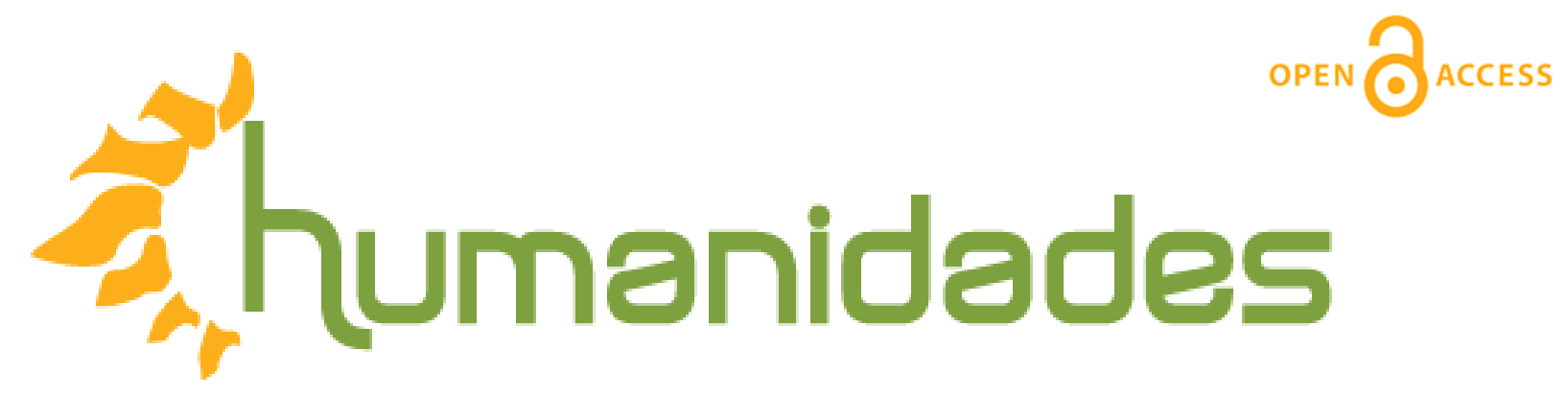

Revista de la Escuela de Estudios Generales, Universidad de Costa Rica

Enero-junio, 2017 •Volumen 7, número 1 • EISSN 2215-3934•pp. 1-43

Recibido: 03-Septiembre-2016 Aceptado: 02-Noviembre-2016

\title{
El proceso de iniciación en una práctica cultural. El caso de seguidores de Carlos "Indio" Solari
}

DOI: http://dx.doi.org/10.15517/h.v7i1.27619

\section{Nicolás Aliano}

Consejo Nacional de Investigaciones Científicas y Técnicas (CONICET) y Universidad Nacional de San Martín, Argentina.

Correo electrónico: nicolasaliano@ hotmail.com 


\title{
El proceso de iniciación en una práctica cultural. El caso de seguidores de Carlos "Indio" Solari
}

\section{Resumen}

El artículo propone sistematizar el análisis del proceso de afiliación a una práctica cultural concreta en el mundo popular contemporáneo. Así, se exponen los relatos de iniciación de algunos seguidores de Carlos "Indio" Solari. En estos se destacan las especificidades de dicho proceso de afiliación, en contraste con otros casos; asimismo, los efectos subjetivos que se promueven en estos seguidores, ligados a la conformación de un espacio individualizante en el marco de tramas sociales relacionales en las que inscriben sus prácticas.

\section{The Initiation Process into a Cultural Practice. The Case of Fans of Carlos "Indio" Solari}

\begin{abstract}
The article proposes systematizing the analysis of the affiliation process to a particular cultural practice in contemporary popular world. Exposed the "initiation stories" from fans of a rock musician: Carlos "Indio" Solari, as part of the reconstruction of some aspects of their biographies. On this line, it seeks to highlight the specifics of this affiliation process -in contrast to other cases- and the subjective effects that promotes in these fans, linked to the formation of an individualizing space within relational frames in which enrolling their practices.
\end{abstract}

Keywords: Popular culture, music, cultural consumption, lower class, biography. 
¿Cómo alguien llega a convertirse en un consumidor comprometido de un producto cultural? Este artículo retoma la pregunta anterior -pregunta que se planteó Howard Becker (2009) en su estudio clásico sobre los consumidores de marihuana- para examinar cómo se produce el proceso de iniciación y afiliación a una práctica cultural en las clases populares de la Argentina contemporánea. Tras indagar en los relatos autobiográficos de algunos seguidores de un músico de rock argentino, el objetivo es comprender cómo estos individuos se afiliaron a un mundo musical específico y se construyeron como seguidores: ¿por qué se sintieron atraídos por el rock en general y por esta figura en particular?, ¿cómo desarrollaron esta vinculación con el paso del tiempo? y ¿qué tipo de implicación subjetiva se establece con este consumo? Para ello, se exponen los relatos de iniciación de los seguidores en el marco de la reconstrucción de algunos aspectos de sus biografías.

¿De qué modo han sido pensados estos procesos en el análisis de las clases populares? Existe una vasta literatura que ha destacado el papel activo de los consumidores en la "apropiación cultural" de diversos recursos de la cultura de masas. En sintonía con planteos como los de De Certeau (2008) y Grignon y Passeron (1991) se ha destacado dicho carácter activo y creativo de las culturas populares, en crítica tanto a posiciones de corte frankfurtiano (que enfatizan en la pasividad de la recepción cultural) como de filiación bourdieuana (que subrayan la heteronomía cultural de las clases populares). Sin embargo, desde estos enfoques, más allá de destacar el carácter "activo" 
de los procesos de recepción cultural como instancia de creación de sentidos, no se han visibilizado las mediaciones (Hennion, 2010) concretas que conducen a una persona a la implicación con un consumo cultural. Asimismo, la manera en la que ello sucede al interior de una perspectiva biográfica ha sido escasamente tematizada.

En este marco, se busca dar cuenta del proceso diacrónico de conformación de una afición hacia un producto musical popular. En línea con exploraciones contemporáneas de la sociología de la música, como las de Hennion (2010) y Benzecry (2012), se enfatiza en el carácter procesual de la conformación de un "gusto", atendiendo a los medios, instancias y espacios en los que ello ocurre, y en los efectos subjetivos específicos que, en el análisis de una biografía, promueve este tipo de vinculación. Desde este movimiento, se muestra que la "afiliación cultural" se modula en un continuo proceso activo, contextuado, abierto y en redefinición.

Así las cosas, el artículo se presenta como una contribución al análisis de los factores a partir de los cuales personas concretas, pertenecientes al universo de las clases populares, llegan a involucrarse en prácticas culturales definidas. Con ello, se pretende contribuir, además, a la literatura más amplia que ha analizado y debatido los modos en los que se produce la iniciación y adhesión subjetiva a diversas prácticas culturales. Se trata esta de una literatura que ha abarcado el consumo de marihuana (Becker, 2009), el aprendizaje del box 
(Wacquant, 2006) y el oficio de soplar vidrio (O ‘Connor, 2012); en el ámbito argentino, la incorporación al movimiento de la Nueva Era (Carozzi, 1999), la afiliación al mundo de la ópera (Benzecry, 2012), las formas de recepción de la literatura de autoayuda (Papalini, 2012), entre otros casos.

Situado en dicho plano, el artículo se plantea un doble objetivo: por un lado, busca destacar las especificidades del caso, elaborando un modelo de afiliación a un consumo musical popular. Por otro lado, en conexión con esto, busca atender y subrayar los efectos sociales que este proceso promueve en la experiencia social en la que se conecta y actúa. El recorrido propuesto para dar cuenta de ello es el siguiente: en primera sección se reconstruyen los "relatos de iniciación" de una serie de seguidores. A partir de la presentación de estos relatos se sistematiza -en la segunda sección- un patrón de iniciación. Por último, en las conclusiones, se condensa el recorrido en la respuesta a dos preguntas: ¿cómo se produce la afiliación a esta práctica cultural? y ¿qué efectos promueve en los seguidores que se afilian a esta?

El análisis se fundamenta en un trabajo de campo realizado entre los años 2009 y 2015 con seguidores del músico de rock argentino Carlos "Indio" Solari. Se llevaron a cabo experiencias de observación participante en diversas escenas de escucha, así como entrevistas en profundidad sobre hábitos de escucha con seguidores que manifiestan una afición activa y duradera por este artista. ${ }^{1}$ La mayor parte de los entrevistados son jóvenes nacidos entre las 
décadas del setenta y fines de los ochenta, de sectores urbanos periféricos, con un nivel de escolaridad bajo y con empleos manuales precarios, la mayoría procedentes de localidades del conurbano bonaerense.

Carlos "Indio" Solari es un músico de amplia trayectoria dentro del rock argentino, exlíder de una de las bandas centrales del "rock nacional" argentino Relatos de la afiliación de las décadas de los ochenta y noventa como lo fue Patricio Rey y sus Redonditos de Ricota. Varios analistas han destacado el lugar central que "Los Redondos" (como suelen denominar a la banda los seguidores) ha tenido en esta tradición (Semán, 2006): una agrupación que tiene sus orígenes en las vanguardias estéticas de las clases medias urbanas, que en la década del noventa se torna masiva, incorporando un público proveniente de sectores populares de las periferias urbanas. Este fenómeno asume dimensiones inéditas en las décadas posteriores, bajo la figura de Solari como solista, a partir del año 2003; en ese marco, los recitales de Solari constituyen actualmente eventos multitudinarios.

Se han seleccionado aquí cuatro historias de fanáticos que participan sistemáticamente de esta escena. Las mismas condensan una serie de rasgos que pueden identificarse en el conjunto más amplio de las historias registradas, en relación a tres aspectos: 1) El tipo de vida que llevan estos fanáticos. 2) El modo cómo empezaron a escuchar lo que escuchan. 3) Los medios a partir de los que profundizaron su vinculación musical. Para abordar 
estos relatos se ha apelado a algunos instrumentales propios del enfoque biográfico. A partir de categorías como "acontecimiento biográfico" (Leclerc-Olive, 2009) o de "bifurcaciones biográficas” (Bidart, 2006), se buscan identificar aquellos acontecimientos significativos sobre los cuales se constituye el "armazón narrativo de los relatos" (Leclerc-Olive, 2009). En este sentido, los relatos, más que concebirse como explicaciones de las propias acciones de los seguidores, son considerados como esquemas narrativos a la luz de los cuales se busca iluminar -tras las recurrencias- un patrón secuencial de momentos y acciones que modulan la vinculación.

Conocí a Leandro en 2009, tenía entonces 26 años (nació en 1983). Leandro vive en Avellaneda - una localidad perteneciente al conurbano bonaerense- y es el mayor de un grupo de amigos con los que asiste desde hace algunos años Te desafía a querer aprender más. Leandro a los recitales de Solari, cuyas edades rondaban por entonces entre los $18 \mathrm{y}$ los 21 años. Leandro tiene un programa de radio y canta en una banda que formó recientemente. Hasta poco antes de conocerlo trabajaba como cadete de un banco, pero actualmente se considera "desocupado". Leandro, además, cuenta con estudios secundarios completos y con una larga lista de empleos ocasionales. En uno de aquellos encuentros, una tarde de domingo en Avellaneda, Leandro contaba de su historia con la música:

Yo arranqué escuchando lo que escuchaban en mi casa, que era tango y folclore y mucha música flamenca. Mi viejo era fanático de todo eso. 
Por ahí venía más que nada la parte de la música que yo escuchaba. Rock en mi casa no se escuchaba mucho porque mi viejo era como que el rock mucho no le gustaba, por los mensajes. Después sí llegó una etapa donde escuchaba más que nada música que sonaba en la radio, o sea podía escuchar rock, como podía escuchar pop, como podía escuchar cumbia, como podía escuchar bolero; eso ya entrando en los diez años en adelante, digamos. Y fue así hasta que llegué a la secundaria. En la secundaria me crie escuchando mucho Los Decadentes [banda de rock argentina] y cumbia básicamente, o sea más que nada por lo romántico y lo divertida para bailar. Cuando iba a bailar tenía un grupo de amigos que siempre escuchaban cumbia (Leandro, comunicación personal, 25 de marzo de 2009).

En el marco de ese relato, Leandro cuenta que fue alrededor de sus 17 años cuando empezó a vincularse con "otra gente", que lo llevó a acercase al mundo del rock y en especial a Los Redondos. Así describe lo que vive como un "quiebre" en su relación con la música y en la elaboración de sus gustos:

Yo tenía otra clase de amigos, escuchaba otro tipo de música y tenía otra forma de pensar y como que no me sentía cómodo. Y un día, un grupo de amigos me dice: "escucha esto", y escuche. Era un tema de Los Redondos, "Vencedores vencidos”; “copado dije, ¿qué más tenes?” Y ya no fue un tema sino todo el disco y otro disco y quiero más y quiero 
más y... Bueno, acá estoy, me terminó atrapando. Así empecé a conocer otro grupo de chicos que venía escuchando rock de toda su vida porque la familia escuchaba rock, y ellos fue como que me influenciaron a mí diciendo “bueno, escuchá Redondos, escuchá Nirvana también” y ahí fue que me empecé a involucrar en el mundo del rock (Leandro, comunicación personal, 25 de marzo de 2009).

Las preferencias musicales que fue adoptando Leandro, en su descripción, están mediadas por las relaciones interpersonales en las que se fue involucrando, y en ellas y a través de ellas es que fue definiendo un modo específico de comenzar a vincularse con la música. Así lo describe el mismo:

Creo que fueron mis amigos los que más me influenciaron, ni Internet, ni la radio ni todo lo otro, sino más que nada una cuestión social. O sea: mis amigos para mal y para bien, los que me hicieron escuchar rock y los que no escuchaban rock, fueron los que me hicieron inclinar al rock. Los que me hicieron escuchar rock porque me mostraron otro mundo diferente y los que no me hacían escuchar rock era justamente porque no me gustaba el mundo ese en el que yo estaba. Entonces creo que eso fue lo que me influyó para que escuche lo que estoy escuchando hoy: mis amigos, los positivos y los negativos. 
O sea yo notaba que estando en un lugar... pertenecer al rock te da cierto nivel cultural. Te desafía a querer aprender más y la cumbia no me desafiaba a nada. Digamos, porque las letras de cumbia tienen eso que te mueven, que está bien, nada más. Claro cuando escuché Redondos me promovían un desafío de “iy esto por qué viene?". Uno lo puede llegar a entender o no, pero me promovió un desafío el hecho de investigar, el hecho de querer mejorar... en mi caso fue eso (Leandro, comunicación personal, 25 de marzo de 2009).

En el relato de Leandro se observa la importancia de la búsqueda de una nueva identidad como resorte para un "cambio" personal: "no me gustaba el lugar ese donde estaba". El encuentro con otras personas le mostró "un mundo diferente", le generó un "desafío", "un impulso de querer mejorar" $\mathrm{y}$ en el relato de Leandro aparece como un momento decisivo en su "quiebre" musical y su acercamiento a Los Redondos. Pero además del hecho de vincularse con un nuevo grupo de amigos, Leandro recuerda otros dos momentos importantes en relación al desarrollo de su gusto por Los Redondos. Uno de ellos fue cuando lo invitaron a una sala de ensayo a escuchar a una banda de amigos hacer covers de Los Redondos. El otro tiene que ver con un episodio familiar, que recuerda como una "imagen" muy fuerte en su relación con la música: 
Tengo la imagen de una Navidad, tratar de arrancarla con un tema que me guste; como en su época ya me gustaban Los Redondos, en esa Navidad dejé a las 12 de la noche el grabador preparado -en la época del grabar con cassette ¿no? que antiguo-; tenía el cassette preparado, todo, para poner JiJiJi a las 12, cuando empezaran los cohetes, para arrancar con JiJiJi el día. Y bueno estábamos ahí y justo cuando faltaba un poquitito para brindar yo tenía la copa y apretaba. Claro, era "tic", y apretaba la tecla y brindábamos y arrancaba con la música. Y mi viejo nunca le había prestado atención, y ese día que lo puse no sé por qué se le dio que, esa fue la imagen de decir "este tema me gusta" (Leandro, comunicación personal, 25 de marzo de 2009).

El relato muestra la importancia de las aprobaciones familiares en la experiencia de Leandro: la ligazón afectiva con el padre y la atención de éste a la música de su hijo es recordada como una experiencia pregnante en su memoria, y forma parte de esa trama que liga a la música con las vivencias que consolidaron la elección de un "camino" musical. El tercer episodio que reafirmó su fanatismo fue el haber podido asistir a un recital del Indio Solari, luego de la separación de Los Redondos (a quienes Leandro nunca llegó a ver en vivo): "Fue en el 2005 -relata - era la primera vez que iba con un grupo de amigos que aún no conocía. Y fuimos, éramos once. Yo estaba recontra entusiasmado porque era ver a mi ídolo... Recuerdo con una emoción, con un llanto... que hasta el día de hoy me acuerdo de ese recital". 
En su trayectoria, a los factores referidos (la voluntad de cambio personal, el encuentro con un nuevo grupo de amigos y experiencias, la aprobación familiar), se suma la experiencia del recital como experiencia extraordinaria que termina de "fijar" su fanatismo: "tengo casi todas las imágenes y casi toda la secuencia de lo que pasó presente", agrega.

Leandro escucha otra música además de Los Redondos y el Indio Solari: otras bandas de rock argentino e internacional. "Sin embargo -dice- Los Redondos despertaron 'una llama especial', "Los Redondos están siempre”. Leandro confiesa que su fanatismo lo ha llevado a imitar al Indio Solari: "a veces me pasa como que me hago el Indio y hablo medio con la voz así y me hago el filosófico", "pero a veces es inconsciente porque uno los ve tanto, los escucha tanto, que por ahí se te terminan pegando". También suele imitar al Indio cuando canta: "me paro frente al espejo y como que soy el artista, imito movimientos, o canto". Leandro concluye: "la música genera eso, me lleva a varios lados".

Esteban nació en 1974, está en pareja y tiene 3 hijos. Al momento en que se inició el contacto, en un recital de Solari en diciembre de 2008, tenía 35 años. Esteban es el mayor de tres hermanos, con quienes siempre asiste a los recitales del Indio: Matías, de 23 años y Gabriel, de 18. A este grupo se suma su cuñado Lucas, de 26, y un amigo del barrio, Nahuel, de 24. Todos trabajan

\section{Vencedores vencidos marcó mi vida. Esteban}


como obreros de la construcción, con excepción de Nahuel que es repositor en un supermercado.

Esteban lleva varios años escuchando a Los Redondos y al Indio Solari y asistiendo a sus presentaciones; se suele declarar alternativamente "hincha", "fanático", "seguidor", del Indio, subrayando la admiración que siente por su persona. Así relata Esteban su trayectoria musical y la "inflexión" que significó para el conocer la música de Los Redondos:

Cuando yo empecé, primero escuchaba lo que te ofrecía el sistema, en ese momento era lo que te ofrecía la radio. Pero hubo un punto de inflexión, que cambio mi vida para siempre, que fue cuando escuche Los Redondos. Y que me acuerdo y me emociono. Por eso te digo la conmoción en la que estoy. Tener todo ese recuerdo ya me emociona (Esteban, comunicación personal, 19 de diciembre de 2009).

Similar a lo que ocurre con los relatos de conversión, Esteban interpreta su biografía a partir de un evento que resignifíca su trayectoria y la percepción de su propia identidad (Carozzi y Frigerio, 1994). Esta “inflexión”, a su vez, no se evoca de manera abstracta; en su relato de iniciación aparece, como en otros casos, la evocación de un acontecimiento preciso, contextuado y afectivamente connotado: 
Fue hace veinticinco años. Empecé a escuchar porque escuche un tema que me conmovió: Vencedores vencidos. Vencedores vencidos marcó mi vida. 'Y ahora tiro yo porque me toca en este tiempo de plumaje blanco' [recita un fragmento de la lírica]. Yo en ese momento no entendía nada, pero me llegó el asunto. Me acuerdo cuando la escuché. Estaba allá en Villa Cacique, un pueblito de tres mil habitantes. Mi viejo empleado de fábrica. Y teníamos un grabadorcito arriba de la mesada. Y escuchábamos un programa que se llamaba "Vivamos la aventura", en la radio. Hace muchos años, eh, te estoy hablando de 1984 u 85. Más o menos ahí era el asunto, y el Indio ya venía de allá atrás. Y por ahí, empieza [imita con la voz los acordes de Vencedores vencidos] "Y ahora tiro yo porque me toca" [cantando] Imagínate, era pibito, yo me lo imaginaba al Indio que tenía rulitos y pelo largo, ¡nada que ver cómo me lo imaginaba! Encima yo creía que se llamaba Patricio Rey. Después nos empezamos a dar cuenta que Patricio era un personaje ficticio, que estaba en el subconsciente colectivo y cosas así (Esteban, comunicación personal, 19 de diciembre de 2009).

Esteban vive en un barrio, según su definición, "humilde", "de gente laburante". Allí se suele encontrar con sus hermanos y amigos a escuchar al Indio, y de hecho siempre ha buscado compartir su gusto con sus hermanos menores. "Es que en casa siempre se escucharon Los Redondos, y el puntapié inicial en la familia lo dio él", cuenta su hermano Matías. "Muchos momentos 
compartidos. Tenemos vínculos a través de esto, y a nivel familiar también", aclara Esteban. Sin embargo en estos intercambios el fanatismo de Esteban parece destacarse por sobre el resto, y ese "vinculo colectivo" adopta la forma de una relación más individualizada con su afición; en relación a ello es que confiesa: "a veces parece una actitud egoísta, porque a veces rompo las pelotas con el Indio". "A veces, me dicen: 'poné otra cosa, dejame de hinchar con el Indio". Esteban reflexiona: "a veces quedo como muy fanático, enfermo". Y ese apego intenso hacia la música de Solari, incluso lo vuelca ahora sobre sus hijos: "Yo no le impongo a mi hijo que escuche lo que me gusta a mí, porque ellos escuchan otras cosas, son bebés... Pero Chofi, que tiene un año ya me dice 'dale, dale" Esteban concluye: "ya ellos nacen así ¿viste? Genéticamente ya vienen con ese sentimiento. Eso es lo que tiene el Indio Solari, obviamente. No sé cómo hace, porque el loco es mágico, viste...”

Ezequiel tiene 28 años, lo conocí en la previa a un recital del Indio Solari en diciembre de 2008, donde estaba junto a un primo y dos amigos del barrio. Ezequiel está en pareja, tiene una hija de dos años, trabaja como albañil para una empresa de construcción y vive en Laferrere, una localidad del conurbano bonaerense. Tiene hasta el primer año del colegio secundario completo. Ezequiel cuenta el modo en que se acercó a Los Redondos de la siguiente manera:

\section{Me enganchó. Ezequiel}


A Los Redondos los empecé a escuchar por un primo mío, a los 13 años. Iba a la casa de mi primo, que ahora tiene cuarenta años, y yo era chico e iba a la casa de él y siempre estaba escuchando esa música, siempre estaba escuchando algo, viste. Y yo me ponía a escuchar y me atraía el ritmo, yo nunca había escuchado eso. Le preguntaba a él cómo se llamaba el grupo ese, y ahí mi primo me pregunta: ¿te gusta? Y me dice esto, todavía me acuerdo las palabras: "anda a mi pieza, debajo de la almohada tengo un libro, tráelo". Y fui y los busqué y era un libro de Los Redondos, contaba la historia de Los Redondos, letras de temas, reportajes al Indio... y entonces me dice: "bueno, si te gusta llevatelo, leelo, después me lo traes".

Y ahí empecé a leer el libro, empecé a grabar los casettes. Y bueno, empecé a escuchar esa música, a escuchar y escuchar y bueno, muchas de las letras no las entendía pero me gustaba el ritmo, era un ritmo que me pegaba, viste. Los Redondos me empezaron a provocar algo que no me provocaba otro músico... ponele que escucho un tema que me gusta mucho y se me eriza la piel viste... un tema que lo relacionas con vos ponele... me enganchó (Ezequiel, comunicación personal, 20 de marzo de 2009).

En el relato se destaca la importancia de la ligazón afectiva previa con seguidores ya socializados en la afición, y la importancia de ese vínculo en 
el "enganche" de Ezequiel: "todavía me acuerdo las palabras", evoca. Una vez que "se enganchó", Ezequiel empezó a "investigar", como él mismo señala, buscando más información, consiguiendo grabaciones de mejor calidad, preguntándole a gente más grande que tenía experiencia en haber visto los recitales de la banda:

Cuando salieron los compact también empecé a trabajar, entonces me empecé a comprar los compact, y bueno, llegue a juntarlos a todos. Del único que llegue a juntar toda la colección fue de Los Redondos. Empecé a investigar viste, me interesaba saber de las raíces del grupo, del Indio, como se formó el Indio. Y empecé a escuchar de gente grande, que ya lo venía escuchando, que decía que ya lo habían ido a ver en ese tiempo, '95-‘96. Y me llamaba la atención pero no podía ir a verlo, tenía dieciséis años aproximadamente. Y cuando cumplí dieciocho fui a verlo. Lo único que me provoca eso son Los Redondos viste, una adrenalina... te provoca algo bueno... algo tiene el chabón, sabe cómo transmitir algo viste (Ezequiel, comunicación personal, 20 de marzo de 2009).

Otro momento que Ezequiel recuerda como clave para su afición tiene que ver con las charlas con un compañero de trabajo más grande, con el cual podía conversar e intercambiar opiniones sobre sus preferencias musicales. En la historia de Ezequiel se pone en primer plano la importancia de las 
relaciones próximas en las que esta entramado para el acercamiento al objeto. Relaciones atravesadas por el afecto, con personas que ya manifestaban la afición. "A los diecisiete empecé a trabajar de mozo en un restorán y conocí a un chabón más grande, de treinta, y él me hablaba de Los Redondos" -cuenta- "y nos poníamos a hablar de Los Redondos y así me fui enganchando más, me provocaba más ganas de ir a verlo, y después que fui a ver Los Redondos fui a ver otras banda pero no es lo mismo..."

Ezequiel cuenta que en total son seis primos con los cuales actualmente suele ir a los recitales, junto con algunos amigos y las novias de todos ellos: "y algunos hijos incluso... mi sobrinita tiene 6 años y a ella le pones un tema y ya te dice cómo se llama y en que disco está". Ezequiel además suele comprar, cuando puede, algunas revistas que tienen información sobre rock, y hace un tiempo que se viene rapando y usando unos anteojitos similares a los del Indio en busca de imitar su estilo: "a mi señora le gusta", dice sonriendo, "ella está enamorada del Indio".

A su vez, Ezequiel quiere empezar a llevar también él a su hija a los recitales:

A la nena no la llevo todavía, tiene dos años, pero cuando sea más grande la voy a llevar... ya está conociendo la música, porque le ponemos música y se engancha, y el tema es cuando ve una foto del Indio o alguna remera dice "papa", porque como me vio mucho 
tiempo pelado a mí y con anteojos... cuando ve alguna imagen del Indio dice "papá", "mira mami, papá". También tenemos fotos del Indio en un cuadrito, en la pieza, en el comedor... y al que pregunta donde está tu papá, para ella está ahí, en la foto del Indio (Ezequiel, comunicación personal, 20 de marzo de 2009).

Fabián nació en Lomas de Zamora, otra localidad del conurbano bonaerense, en 1983; hijo de padres separados, creció con su madre y su padrastro. Al momento en el que fue contactado, en el marco de un recital de Solari en 2008, tenía veintiséis años. Fabián empezó a escuchar a Los Redondos a los ocho años: "por culpa de mi hermano", dice bromeando. Su hermano es cinco años mayor que él, pasó parte de su infancia en la casa de su tía y Fabián recuerda que iba a esa casa y que ahí lo encontraba siempre escuchando Los Redondos en el patio, "en el fondo" de aquella casa. Fabián relata que por aquel entonces el escuchaba música "más tranquila": R.E.M, Queen, UB40 y que no le gustaba Los Redondos porque no los entendía, pero que empezó a prestarles atención a partir de un momento preciso, que evoca emocionado:

Un día en el que me había sacado "diez" en el colegio, en segundo o tercer grado... volví a la casa de mi tía re contento, gritando ¡me saqué un diez, me saqué un diez! y escucho un tema que venía desde el fondo de la casa: era "Motorpsico", un tema tranquilo, profundo, y hubo una

\section{Los Redondos conformaron mi vida. Fabián}


frase que me impactó: 'y los niños no juegan dados quizás...' (Fabián, comunicación personal, 28 de Febrero de 2009).

Fabián ha anclado en su memoria un momento de alegría, ligado a un "éxito escolar", con la experiencia musical que estuvo imbricada en ese mundo vital, en el que ese tema -"tranquilo" y sobre todo, "profundo", que llegaba "desde el fondo" de aquella casa- estaba entramado y actuante. La frase que Fabián rescata, "y los niños no juegan dados quizás", sin terminar de entenderla, de algún modo misterioso lo "impacto": ese día, en ese momento, Fabián sintió que estaba interpelando su propia niñez y que aquel era un quiebre en su trayectoria. Fabián lee allí, en esa frase, su niñez como cifra. Lo significativo es que la frase aludida, en la lírica de la canción está predicando algo sensiblemente diferente a lo que él luego rescata evocativamente. En ella se escucha: "mi dios no juega dados, quizás... este a mi favor"; y la frase tematiza, precisamente, la posibilidad de volverse un sujeto activo del propio destino. Fabián cuenta que fue a partir de entonces que comenzó a prestarle atención a Los Redondos, y fue por esa época - en la que se escuchaban cassettes y en la casa de Fabián no había muchos- que empezó a sacarle ese casette de Los Redondos a su hermano y a escucharlo el, hasta apropiárselo.

El segundo momento que destaca como un impulso para acentuar su fanatismo fue cuando se compró su primera remera con la imagen del Indio Solari, y un tiempo después fue a su primer recital, en Córdoba: "tenía 14 
años... me fui sin avisar en casa". "Nunca había visto tanta gente junta", dice, "fue impresionante". "Después de eso me fui de mi casa, se complicaron las cosas, me metí en cosas más raras..." Una "etapa oscura", "una etapa borrada", dice, aludiendo a su relación con ciertas drogas.

El tercer momento que identifica como base de su gusto por Los Redondos es cuando su padrino le regaló su primer disco: "esto te lo traigo para vos", relata impostando la voz como si el que hablara fuera su padrino. "Ese compact se gastó de tanto pasarlo", cuenta. Después de eso Fabián empezó a comprarse los compacts el mismo y a partir de ahí es que, según cuenta, se hizo "más ricotero" (así se suele denominar a los seguidores de la banda). Y fue entonces cuando empezó a ir a ver a Los Redondos en grupo: "era una pandilla de unos veinte, pero los más amigos éramos unos diez..." Fabián cuenta que en realidad él fue el "precursor" de todos los ricoteros que están "en el fondo" (así llama a los que, dentro del barrio, están más distantes de su casa). Por entonces esos amigos le decían que escuchara Los Charros (una banda que, según dice, estaba de moda en ese momento) entonces él les respondía que sí, pero a cambio de eso después les hacía escuchar Los Redondos. En esa dinámica de intercambios, comenta que algunos amigos lo cargaban diciéndole que escuchaba "música pasada de moda": "Es que los vagos no entendían la letra, viste... porque vos para escuchar esta música tenés que entenderla... y los vagos viste no daban pie con bola". 
La música de Los Redondos le evoca a Fabián una infancia problemática, llena de recuerdos de amistades, seres queridos y buenos momentos, pero también de conflictos familiares, ausencias y pérdidas:

Los Redondos conformaron mi vida viste... los recuerdos, recuerdos crueles de la vida que uno pasó. Para no olvidarme que tuve una pobreza. Además yo escucho un tema y me acuerdo lo que pasó, yo escucho un tema y me acuerdo que la están cagando a palo mi vieja. "Ultimo Bondi" [disco de Los Redondos] me hace acordar a mi primo, porque lo escuchábamos juntos... y lamentablemente lo atropello un auto y bueno... partió (Fabián, comunicación personal, 28 de Febrero de 2009).

Observamos aquí, en línea con lo señalado en trabajos como el de Spataro (2011) con seguidores de Arjona, cómo las situaciones de aflicción o crisis pueden desencadenar un trabajo personal y reflexivo de búsqueda de sentidos a partir de la experiencia musical. Fabián se fue de la casa muy chico, en varias ocasiones, y nunca terminó el secundario. Finalmente se mudó a Banfield en 2001, luego de conocer a su actual pareja, con la que tiene tres hijos. En Banfield conoció nueva gente y armó una banda de música, de "covers" de Los Redondos. Fabián alternaba así las actividades con la banda, las obligaciones familiares, y la actividad laboral; pero ese arreglo, "se le empezó a complicar": "los otros eran todos solteros, el único casado era yo, y se 
complica por la familia... porque además laburaba 12 horas en un lavadero industrial y no estaba nunca en casa..." Fabián "se abrió" de la banda pero siguió escuchando Los Redondos y yendo a los recitales de Solari. "Los Redondos es parte de mi vida, lo llevo en la piel' dice, mientras muestra un tatuaje del Indio. "Hace diez años atrás no sabes lo que era: remeras, pantalones, ponía 'Redondos' por todos lados... hay gente que me dice "redondito"”. Además confiesa que a veces baila como el Indio y se pone los anteojos como él. Actualmente trabaja 10 horas por día en una fábrica de polímeros, y es el único que trabaja de los miembros de su hogar, que comparte con sus hijos, su esposa y su abuelo.

Elaborar y sostener la afición les permite a estos fanáticos hacer una "presentación de su persona" a través de estos relatos autobiográficos, en los que se subrayan sus actividades vinculadas con la música. Pero además, en los relatos se observa la activación de un proceso que no tiene que ver con la mera identificación con un "rol de fan", sino con una dinámica subjetiva más compleja, en la cual estas personas, a partir de su conexión con la afición, se descubren reflexivamente a sí mismas: "Los Redondos conformaron mi vida", señala en este sentido, como giro reflexivo, Fabián. Este proceso, vinculado a la tematización del propio "yo", tiene efectos individualizantes en los modos en que estos seguidores buscan su propia comprensión en el marco de otras relaciones. En este cuadro, podemos reconstruir un proceso de

\section{El proceso de afiliación. Un modelo secuencial}


afiliación secuencial (Becker, 2009) recurrente, elaborado por inducción analítica a partir de las historias recuperadas.

Todos comenzaron a escuchar la música del Indio / Los Redondos a una edad temprana (entre los 8 y los 18 años) en el seno familiar (por hermanos mayores fundamentalmente, pero también por influencia de padres, tíos o primos) y en menor medida por las relaciones amicales cercanas, que en algunos de los entrevistados se da como un paso posterior a que "el enganche" (Benzecry, 2012) se produjo. Todo ocurre como si, en un momento investido afectivamente, siendo significativo para la experiencia vital del "oyente", la música - pero no la música en abstracto, sino un tema en particular, un ritmo, una estrofa, una frase, una melodía- "prendiera" y cautivara a quien la escucha: "me atrapó", "me hipnotizó", "me impactó", "me enganchó", son expresiones recurrentes para dar cuenta de este instante de revelación (Benzecry, 2012) singular, contextuado, e investido afectivamente.

"Fue una frase de Motorpsico", "escuché Vencedores Vencidos y me cambió la vida", son algunas de las expresiones que -más allá de la casuística y la reconstrucción evocativa de la experiencia- muestran recurrentemente ese instante de la revelación que "atrapa" al sujeto a la vez que funciona como momento de subjetivación: "me cambio la vida", "explica lo que soy”. En este punto muchos de los relatos asumen la forma de un relato de conversión, en tanto a partir de ello se produce una modificación en el hilo conductor de la 
propia biografia (Carozzi y Frigerio, 1994). En este "encuentro" revelador, entonces, el lugar de las redes familiares-amicales para "conocer" esa música, así como la importancia del vínculo afectivo previo con estas personas, resulta un factor decisivo para muchos de estos seguidores.

Otro factor que incide en que este "encuentro" se produzca se vincula, en los relatos de muchos de los entrevistados, con la presencia de experiencias de aflicción: angustias, tensiones, conflictos, momentos críticos en la vida. Dichas experiencias producen una fractura, un quiebre en la continuidad subjetiva, y conducen a la búsqueda de una redefinición de la propia identidad personal a partir de relacionarse con esta música en busca de claves (tal como observamos, por ejemplo, en el relato de Fabián).

Luego de ello existen una serie de acciones y situaciones que llevan a organizar y desarrollar esa atracción inicial: a) hacerse de un momento y un lugar para la escucha personal y volverla sistemática; b) comprarse, coleccionar y atesorar "la discografía completa" (Ezequiel me dice: "de Los Redondos es de los únicos que tengo todos los discos originales, en cassette y en $\mathrm{CD}$, y las versiones piratas y los inéditos"); c) reunirse con amigos a discutir interpretaciones; d) leer libros y revistas sobre música, consultar información en internet. Esas prácticas aparecen recurrentemente en todos aquellos que quieren dar "un paso más" al de la escucha ocasional o puramente recreativa. En este sentido, estos fanáticos comienzan a gozar de 
la música no porque "se dejan llevar" (o no solo por ello), sino porque activamente se preparan para tal fin: "un desafío a querer aprender siempre más", como dice Leandro, que impulsa la acción de "gustar" siempre hacia delante. Entonces, para estos "seguidores", quien no ha experimentado de ese modo la escucha, quien no la ha desplegado, cultivado y sostenido en el tiempo, no es un "fanático".

A la vez, expresiones como "me conmueve", "me llega", "me eriza la piel", son recurrentes para expresar la adhesión diferencial y la investidura emocional a la música del Indio o Los Redondos, en relación a otras propuestas que "no llegan a conmover". Y estas prácticas suelen tener un sentido singularizante, en el seno familiar o al interior del grupo de amigos o vecinos: "en mi familia el más ricotero soy yo", "mis amigos me cargan pero no entienden la letra", "yo fui el precursor", "hay gente que me dice redondito", etc.

De modo que existe un entramado por el cual se cultiva previamente la "emoción" y esta preparación tiene como culminación la experiencia del recital en vivo, a la cual se llega generalmente luego de una carrera de preparaciones, anhelos y expectativas ("mis viejos de más chico no me dejaban", "hablaba con gente más grande que me contaba lo que era"), y aparece como el paso necesario para "fijar" el fanatismo. En este sentido, en relación a los procesos de conversión religiosa algunos trabajos han mostrado 
la importancia de la participación en experiencias que desafían los esquemas cognoscitivos actuales: como sugieren Carozzi y Frigerio (1994) la participación en "experiencias no-ordinarias parecen facilitar y ayudar a sostener la conversión" (1994, p. 18).

De un modo similar, la experiencia del recital, para estos seguidores suele ser vivida como un desafío a los propios esquemas cotidianos, que lleva a intensificar la afición. A su vez, se configura allí un "contrato de escucha” ysobre todo con la recurrencia- se aprenden los modos "correctos" de expresar la emoción y experimentar el fanatismo, incorporando regulaciones y aprehendiendo prácticas como "llevar banderas". Así, la interacción recurrente en esta escena permite fijar el sentido de la experiencia, y alcanzar una comprensión común de la misma.

Una vez que "enganchados", los fanáticos buscan performar los modos de hablar, cantar o moverse del Indio Solari. En tal sentido, los fanáticos literalmente incorporan en sus prácticas aspectos de la gestualidad, los modos de hablar o de moverse, o la apariencia del músico. A su vez, en este camino, algunos fanáticos dan "un paso más", involucrándose ellos mismos en prácticas musicales: aprender a tocar un instrumento, o conformar una "banda tributo", a partir de lo cual la "personificación" puede ser más o menos permanente. 
La presencia de esta personificación emparenta el caso con otros, de apropiaciones similarmente miméticas por parte de los seguidores, como el de Gardel (Carozzi, 2003), la cantante de cumbia Gilda (Martín, 2006) o, fuera del medio argentino, el de Elvis Presley (Rodman, 1996). ${ }^{2}$ En relación con este punto María Carozzi (2006), partiendo del concepto de mitologías mínimas de Calavia Saez (1996), observa que la capacidad de volverse actuables de algunos personajes, su "performabilidad", radica en que poseen un código restringido de gestos, voces y ropas "que los tornan personajes, y por lo tanto actuables" (2006, p. 105).

Esta estereotipia, en el caso de Solari, se ve intensificada debido a que, más allá del ámbito de los recitales, este siempre ha buscado limitar sus apariciones en medios públicos (con lo cual son prácticamente inexistentes las imágenes suyas por fuera de su rol de cantante en el momento en vivo), facilitando ello su performabilidad. Un elemento más cabe destacar aquí: el hecho de que la figura de Solari se sustraiga del espacio público y restrinja sus apariciones promueve a la vez el proceso de su sacralización.

Carozzi (2006) destaca que el hecho de que las biografías que circulan de algunos personajes sean mínimas puede contribuir justamente a la extensión de su culto y la aceptación de su carácter milagroso. Así, la autora ha sugerido, para el caso de los seguidores de Gardel (Carozzi, 2004), que el hecho de que se desconozca buena parte de su vida privada, junto al interés 
que suscita develar el "misterio Gardel”, refuerza el culto a su persona. Esta dimensión se encuentra igualmente presente entre los seguidores de Solari y el "misterio" sobre su vida personal.

Un ejemplo de ello lo ofrecía Esteban en su relato, al referir que en un principio imaginaba que el Indio "tenía rulitos y pelo largo" y "que se llamaba Patricio”. En esta línea, Ezequiel expresa consideraciones sobre la vida privada de Solari, recurrentemente manifestadas por los seguidores a modo de conjeturas:

Tengo un libro que salió del Indio, que decía que él a veces sale medio disfrazado, para que no se den cuenta que es él. Disfrazado con alguna gorra, anda a saber, porque sino pienso que debe ser un quilombo de gente. ¿Imaginátelo caminando por acá, ponele? Y él como que tiene una fobia a la gente. La fama te debe hacer sentir incómodo ¿viste...? Tanto que te siguen los periodistas, o la gente que se te tira. Y el chabón viste que nunca sale en la televisión, es contra eso; parece que no le gusta mucho la farándula, estar dando notas y eso... No sale casi nunca. Siempre siguió ese ritmo, desde que estaba en Los Redondos, siempre fueron así (Ezequiel, comunicación personal, 20 de marzo de 2009). 
Ese carácter "misterioso" de la persona de Solari y la circulación de un relato sobre ello entre los seguidores, es lo que habilita a proyectar sobre la figura diversas interpretaciones, que contribuye a reforzar la atribución de carisma y el culto por el personaje.

Por último, un paso final de la afiliación se vincula con transmitir la pasión: se tratará de fomentar la afición por diversos medios (ofreciendo información, "haciendo escuchar", llevando a los recitales, etc.) en hijos, sobrinos, cónyuges o padres que no comparten el gusto. Apelando a categorías de Straus (1976) en relación a los procesos de conversión, podemos concebir esto como el pasaje del individuo "buscador", en tanto explorador creativo y activo, al "agente", en tanto transmisor del sentido de la experiencia.

Benzecry (2012) formaliza un modelo de afiliación cultural a la ópera con el cual encontraríamos fuertes paralelismos en nuestro caso. El modelo de Benzecry incorpora al planteo de Becker de los consumidores de marihuana un "instante de revelación" que antecede a la socialización en un código compartido para la interpretación de la experiencia, aspecto que encontramos simétricamente en nuestro caso: todos los seguidores se sienten cautivados por la música sin tener necesariamente un conocimiento de lo que están escuchando, de cómo decodificarlo o de qué es lo que constituye el goce. Del mismo modo, encontramos un esquema paralelo en relación a la existencia de 
una "estructura de la temporalidad" (Benzecry, 2012) dada por una modulación permanente de la atracción inicial, que se prolonga por diversos medios y situaciones de sociabilidad. Pero habiendo señalado esas similitudes, hallamos algunos matices respecto a este planteo, que nos ayudarán a destacar las especificidades de nuestro caso.

Benzecry enfatiza en el carácter externo a los lazos familiares y las relaciones vecinales; el autor subraya el hecho de que buena parte de estos fanáticos "viven solos" y su acercamiento a la opera tiene que ver "menos con sus disposiciones heredadas que con las relaciones personales que participaron de su introducción a la opera. Son historias vinculadas más con amigos y parejas de aquel momento... que con la familia o la escuela" (2012, p. 101).

En nuestro caso observamos, igualmente, que en la autoproducción del fanático no se trata tanto de "disposiciones heredadas" de la familia o la escuela, así como tampoco de una influencia directa o exclusiva de una "moda musical" massmediática del momento-, sino más bien de la incidencia de diversos vínculos investidos de afecto. Pero aquí sí encontramos que los lazos tramados en el seno familiar y vecinal próximo en la experiencia de socialización posterior a la niñez son centrales en el "enganche” del fanático. En relación a ello hallamos algunos elementos a destacar: en primer lugar la existencia, en muchos casos, de una trama intensiva de relaciones entre 
parientes (hermanos, primos, padrinos, cuñados) en la que suelen circular los consumos.

En segundo lugar, se observa también, en algunos casos, la importancia de las autorizaciones/ aprobaciones familiares, para incentivar o intensificar la afición (como en el caso de Esteban, que señala "mis padres siempre apoyaron esta movida", "tenemos vínculos familiares a partir de esto", o el de Leandro, que evoca como momento significativo de su involucramiento con Los Redondos la noche de navidad que puso una canción y al padre, sorpresivamente, "le gustó").

En tercer lugar, encontramos la importancia asignada por muchos de estos seguidores a "transmitir" la pasión a sus hijos o sobrinos e involucrarlos en la escena. Todo ello da cuenta de la centralidad de los valores de la familia entre estos seguidores y de su importancia en tanto soportes afectivos, y se encuentra en línea con varios trabajos que subrayan la presencia de estos valores en la experiencia relacional de las clases populares (DaMatta, 2002; Semán, 2006; Araujo y Martuccelli, 2012).

En este cuadro, otro contraste además del referido sobre los seguidores de la opera permite especificar y dimensionar la presencia de esta pauta en este grupo cultural. Carozzi (1999) observa, para el caso de las personas que participan del movimiento de la Nueva Era, que la influencia que otras 
personas y contactos podrían haber ejercido en la adopción de prácticas y creencias suele ser suprimida cuando los activistas cuentan su vida. Este estilo de elisión de influencias sociales -sostiene la autora- se constituye en "un 'modelo nueva era' de estructurar la biografía personal o el relato de conversión" (1999, p. 28), y hace visible que en el núcleo doctrinario de la Nueva Era "se halla justamente la sacralización de una absoluta autonomía individual" (1999, p. 29). En nuestro caso, por el contrario, la presencia de influencias, autorizaciones y transmisiones en el seno de diversas relaciones sociales -centralmente familiares- es por el contrario promovida $y$ explícitamente referida en los relatos sobre la iniciación y el sostén de la afición, inscribiéndose en pautas que distan de la idea de una "autonomía personal".

En suma, lo que encontramos aquí son modos de subjetivación en los cuales se halla presente un trabajo reflexivo sobre sí, que muchas veces tiene la forma de una conversión en el sentido señalado por la literatura (Carozzi y Frigerio, 1994): una fractura en la continuidad biográfica que resignifíca la trayectoria y la propia identidad. Pero este proceso tiene lugar, se desenvuelve y se desarrolla, desde una trama relacional de apoyos, intercambios y autorizaciones, y se configura desde los valores que emergen de esa trama. En este sentido, en los relatos de iniciación hay una conexión con una dimensión sagrada de la experiencia (anclada muchas veces en el culto a la figura del 
Indio) que, inscripta en una red de apoyos e intercambios, habilita la reflexión moral y la búsqueda de la superación personal.

En otras palabras: los efectos individualizantes que se percibe que tiene la afición en la vida de estos seguidores, no derivan sin embargo de una concepción que, como un presupuesto existencial, deduce al individuo autónomo de su oposición al grupo social. Parafraseando a Pablo Semán (2007, p. 12), la configuración del individuo es aquí, más bien, una instancia opuesta "transitoria y fugazmente" "al orden colectivo de la familia, la comunidad, el barrio". Este orden es el presupuesto experiencial de los seguidores, en el cual estos se sienten incluidos como parte de una trama de relaciones.

Todos estos fanáticos comparten algunos rasgos recurrentes. Por un lado, comparten ciertas condiciones sociales similares, como el ser habitantes de

Reflexiones finales suburbios urbanos, hijos de trabajadores manuales, tener empleos de baja calificación y remuneración (albañiles, operarios de máquina, feriantes, cadetes, entre las ocupaciones mencionadas. Y más allá de sus pertenencias “socio-ocupacionales", sus historias están atravesadas por la precariedad (en el ámbito laboral, escolar, habitacional) como forma generalizada de las relaciones sociales en que se insertan, que inscribe estas biografías en marcos de inestabilidad y vulnerabilidad. Pero estos elementos, ligados a las 
condiciones de vida, no llegan a dar cuenta por si mismos del común gusto intenso por la música de Los Redondos y el Indio.

Existen otros factores que aparecen en estas historias de iniciación que, como "mediaciones", están orientando activamente a que estas personas se acerquen al objeto cultural y profundicen en su afición, descartando otras opciones de consumo igualmente presentes en sus mundos de referencias musicales (como la cumbia en el caso de Leandro, o la "marcha" en el caso de Fabián).

Lo que encontramos además, en un sentido amplio, es que todos estos sujetos comparten una misma visión "expresivista" de la experiencia estética en sus vidas, como lugar de lo que Tylor (1996) ha denominado "fuentes morales" del yo. Esta concepción se articula en los relatos con una noción de los objetos culturales como canales para el progreso personal, y con un trabajo de producción de sí mismo en la experiencia de escucha. Se trata de una disposición "expresivo-moral" que, vinculada a la idea del esfuerzo interpretativo, hace trabajar los propios esquemas de la experiencia social: cierto malestar en la relación con el mundo, conectado con una aspiración a salir de un contexto visualizado como "mediocre", y con problemas considerados centralmente de índole "personal" o "familiar": las drogas, los amores contrariados, la violencia, la muerte de seres queridos, la pobreza en el hogar. 
Todo ello conduce, en los relatos de estos seguidores, a la búsqueda del ser "auténtico" afirmando lo que se es frente $o$ contra el mundo, pero buscando "elementos y personas capaces de transmitir un anclaje existencial" (Martuccelli, 2013, p. 13). Dentro de estas coordenadas es que se da la microgénesis de este perfil de aficionado. Expresiones como "te desafía a querer aprender siempre más" (Leandro), "te provoca algo bueno..." (Ezequiel), son ejemplos de ese lugar que tiene la experiencia musical en la vida de estas personas, y su utilización como fuente para la propia formación moral.

Sin embargo, esta "disposición" que está en la base de las elecciones de los sujetos, no permite explicar por sí sola el proceso de afiliación a un consumo; y en todo caso, como sostiene Lahire (2004) para "explicar la práctica" debemos valernos de una descripción detallada de su desarrollo. En otras palabras: esta sensibilidad siempre es potenciada, sostenida o promovida por otros factores, ligados a circunstancias situacionales (vínculos afectivos previos con otros aficionados, que provocan la "curiosidad" e introducen a la persona en un mundo desconocido "a investigar"), a búsquedas de una nueva identidad personal (ligadas a la presencia de situaciones de aflicción o de frustración, que encuentran en esta música un medio para redefinir la biografía a partir de un consumo "profundo"), o a la participación en experiencias que desafian los esquemas 
cognoscitivos de los seguidores (como la participación en los recitales en tanto experiencias "extraordinarias").

En consecuencia, encontramos que la afiliación cultural es el resultado de un trabajo de ensamblaje (Latour, 2008; Benzecry, 2012) que, luego de un "instante de revelación", da lugar a una serie de fases y medios en los que se "ajusta" y "modula" la relación con el objeto. Se trata de un prolongado trabajo de acercamiento al objeto de afición, que asume la forma de un "embudo perforado" (Bankston, Forsyth y Floyd, 1981), en el cual entran muchos más sujetos de los que completan la experiencia.

En este cuadro, inspirados en la propuesta de Benzecry (2012, p. 263) de elaborar un modelo del apego estético que considere las mediaciones entre la estructura social y el gusto, ${ }^{3}$ podemos reconstruir la afiliación que caracterizamos como una articulación de: 1) Condiciones sociales y elementos de la experiencia social más amplia (trayectorias laborales, educativas, residenciales, etc.). 2) Disposiciones generales hacia la experiencia estética y musical -que como una sensibilidad extendida conecta esta experiencia con la autoformación-. 3) Ciertas circunstancias situacionales (la participación en el seno de relaciones parentales y redes amicales, vínculos afectivos en los que se implican los fanáticos) que producen el enlace de condiciones y disposiciones en prácticas culturales específicas: la atracción por la música de Los Redondos o el Indio. 4) La 
presencia de experiencias que marcaron duraderamente (experiencias traumáticas o trascendentes vinculadas con la escucha de esta música), que contribuyen a transformar la atracción en una vinculación estabilizada. 5) Competencias que emergen de la práctica y en determinados contextos: la producción de un espacio personal para la escucha, la recopilación de información y de conformación de la discografía, el análisis de las letras, la escucha atenta del "mensaje" que transmite la obra.

Como observamos en los relatos biográficos, estos elementos no se hallan presentes del mismo modo en todas las trayectorias, aunque aparecen buena parte de ellos en cada historia. En algunos casos, los factores ligados a las circunstancias situacionales como contactos con pares o familiares que ya compartían la afición, ganan centralidad para entender el "enganche" (como en el caso de Ezequiel); en otros el peso se desplaza hacia los factores ligados a experiencias traumáticas o de aflicción, que contribuyen a reforzar la afiliación (el caso de Fabián, por ejemplo); y hay otros casos en los que la afición se desata centralmente por búsquedas de un cambio en la propia identidad (como en Leandro o Esteban). Pero en todos los casos se da una sutil mezcla de varios de estos elementos para que la afición se sostenga, prolongue y profundice.

De modo que, parafraseando a Lahire (2004), el gusto por la escucha de una obra no puede deducirse de "un único criterio social de especificación, a saber, 
El proceso de iniciación en una práctica cultural...

la posición en el espacio social"; sino que depende, "del stock de compendios de experiencias incorporados" (2004, p. 140). Y a través de este gusto, entramado y elaborado en esos racimos de experiencias, los seguidores se construyen activamente, en tanto "buscadores".

Así las cosas, esta afición estimula una dimensión reflexiva que los seguidores no encuentran "en otra parte", produciendo efectos subjetivos específicos dentro de la experiencia popular: un proceso individualizante que combina la mirada sobre sí y la conexión con lo sagrado, en el marco de pautas que no responden propiamente a la narrativa de la realización en base a la autonomía personal.

Araujo, K. y D. Martuccelli. (2012). Desafíos comunes. Retratos de la sociedad

\section{Referencias} chilena y sus individuos. Santiago, Chile: LOM.

Bankston, W., C. Forsyth y H. Floyd. (1981). Toward a general model of radical conversion. En Qualitative Sociology, 4.

Becker, H. (2009). Convertirse en un consumidor de marihuana. En: Outsiders. Hacia una sociología de la desviación. Buenos Aires: Siglo XXI.

Benzecry, C. (2012). El fanático de la ópera. Etnografía de una obsesión. Buenos Aires: Siglo XXI. 
Bidart, C. (2006). Crises, décisions et temporalités: autour des bifurcations biographiques. Cahiers internationaux de sociologie, Trajectoires sociales et bifurcations, 120.

Bourdieu, P. (2012). La distinción. Criterio y bases sociales del gusto. Buenos Aires: Taurus.

Calavia, O. (1996). Fantasmas falados: mitos e mortos no campo religioso brasileiro. Campinas: Unicamp.

Carozzi, M. (1999). La autonomía como religión: la Nueva Era. En Alteridades, 9(18). México: Iztapalapa.

Carozzi, M. (2003). Carlos Gardel, el patrimonio que sonríe. Horizontes Antropológicos, 9(20).

Carozzi, M. (2004). Rituales en el horario central: Sacralizando a Gardel en los homenajes televisivos. En Ciencias Sociales y Religión/Ciências Sociais e Religião, 6 .

Carozzi, M. (2006). Antiguos difuntos y difuntos nuevos. Las canonizaciones populares en la década del 90. En D. Míguez y P. Semán (eds.), Entre santos, cumbias y piquetes. Buenos Aires: Biblos.

Carozzi, M. y A. Frigerio. (1994). Los estudios de la conversión a nuevos movimientos religiosos: perspectivas, métodos y hallazgos. En A. Frigerio y M. J. Carozzi (comp), El Estudio Científico de la Religión a Fines del Siglo XX. Buenos Aires, Argentina: CEAL.

Da Matta, R. (2002). Carnavales, malandros y héroes. Hacia una sociología del dilema brasileño. México: FCE. 
El proceso de iniciación en una práctica cultural...

De Certeau, M. (2008). La invención de lo cotidiano 1. Artes de hacer. México: Universidad Iberoamericana.

Grignon, C. y Passeron J-C. (1991). Lo culto y lo popular. Miserabilismo y populismo en sociología y literatura. Buenos Aires: Nueva Visión.

Hennion, A. (2010). Gustos musicales: de una sociología de la mediación a una pragmática del gusto. En Comunicar, 34.

Lahire, B. (2004). El hombre plural. Los resortes de la acción, Barcelona: Bellaterra.

Latour, B. (2008). Reensamblar lo social. Una introducción a la teoría del actor-red. Buenos Aires: Manantial.

Leclerc-Olive, M. (2009). Temporalidades de la experiencia: las biografías y sus acontecimientos En Iberóforum. Revista de Ciencias Sociales de la Universidad Iberoamericana, 8.

Martín, M. (2006). No me arrepiento de este amor. Um estudo etnográfico das prácticas de sacralizacao de uma cantora argentina (Tesis de doctorado). Universidad Federal de Rio de Janeiro, Brasil.

Martuccelli, D. (2013). Prefacio. En Di Leo, P. y A. Camarotti (ed.), Quiero escribir mi historia”. Vidas de jóvenes en barrios populares. Buenos Aires: Biblos.

O 'Connor, E. (2012). Saber hecho carne: la experiencia del sentido y la búsqueda de expertise en el soplado de vidrio. En Benzacry (comp.), Hacia una nueva sociología cultural. Bernal: Universidad Nacional de Quilmes. 
Papalini, V. (2012). Las lecciones de los lectores. A propósito de la recepción literaria. En Alabe. Revista de Investigación sobre lectura y escritura.

Rodman, G. (1996). Elvis after Elvis: the posthumous career of a living legend. Londres: Routledge.

Semán, P. (2006). Bajo continuo. Exploraciones descentradas sobre cultura popular y masiva. Buenos Aires: Gorla.

Semán, P. (2007). Psicologización y religión en un barrio del Gran Buenos Aires. En Debates do NER, 12.

Straus, R. (1976). Changing oneself: Seekers and the creative transformation of life experiences. En J. Lofland (ed.), Doing Social Life. Wiley, Nueva York.

Spataro, C. (2011). ¿Dónde había estado yo?”: un estudio sobre la configuración de feminidades en un club de fans de Ricardo Arjona (Tesis de doctorado en Ciencias Sociales). Universidad de Buenos Aires, Argentina.

Taylor, C. (1996). Fuentes del yo. La construcción de la identidad moderna. Barcelona: Paidós.

Wacquant, L. (2006). Entre las cuerdas. Cuadernos de un aprendiz de boxeador. Buenos Aires, Argentina: Siglo XXI. 
El proceso de iniciación en una práctica cultural...

${ }^{1}$ Parte del trabajo de campo presentado aquí ha sido realizado en Notas colaboración con Mariana López, Nicolás Welschinger y Jerónimo Pinedo, a quienes agradezco especialmente por compartir las entrevistas presentadas. Las mismas fueron llevadas a cabo en el marco del proyecto colectivo "Los géneros musicales populares: producción, circulación y recepción. Identidades Sociales y Música entre los jóvenes del Gran Buenos Aires", dirigido por el Dr. Pablo Semán, a quien también agradezco.

${ }^{2}$ Los distingue sin embargo un factor, y es que a diferencia de todos ellos, Solari está vivo.

${ }^{3}$ En palabras del autor, este modelo incluye: "a) las circunstancias iniciales que producen el acoplamiento o el desacoplamiento de esas condiciones, b) las mediaciones que contribuyen a transformar la atracción inicial en un apego más elaborado y sostenido, y c) los tipos de sociabilidad a los que se incorporan los fanáticos novatos”(Benzecry, 2012, p. 263).

\section{¿Cómo citar este artículo?}

Aliano, N. (Enero-junio, 2017). El proceso de iniciación en una práctica cultural. El caso de seguidores de Carlos "Indio" Solari. Revista humanidades, 7(1), 1-43. doi: http://dx.doi.org/10.15517/h.v7i1.27619 